\title{
Zingiber mioga reduces weight gain, insulin resistance and hepatic gluconeogenesis in diet-induced obese mice
}

\author{
DA-HYE LEE ${ }^{1}$, JIYUN AHN ${ }^{1,2}$, YOUNG JIN JANG ${ }^{2}$, TAE-YOUL HA ${ }^{1,2}$ and CHANG HWA JUNG ${ }^{1,2}$ \\ ${ }^{1}$ Department of Food Biotechnology, Korea University of Science and Technology; ${ }^{2}$ Metabolic Mechanism Research Group, \\ Korea Food Research Institute, Seongnam, Gyeonggi 13539, Republic of Korea
}

Received March 3, 2015; Accepted April 7, 2016

DOI: $10.3892 /$ etm.2016.3331

\begin{abstract}
Zingiber mioga is a perennial herb belonging to the ginger family (Zingiberaceae) that is used medicinally to treat cough and rheumatism in China and consumed throughout Japan. The aim of the present study was to investigate the anti-obesity effects of $Z$. mioga following extraction with distilled water or 70\% ethanol. In 3T3-L1 preadipocyte cells, Z. mioga water extract (ZMW) markedly inhibited adipogenesis, whereas the ethanol extract had no effect. In addition, we conducted $\mathrm{ZMW}$ feeding experiments $(0.25$ or $0.5 \% \mathrm{ZMW})$ in high-fat diet (HFD)-fed mice to examine the anti-obesity effects of $Z$. mioga in vivo. Body weight and serum triglyceride and cholesterol levels significantly decreased in the HFD + ZMW $0.5 \%$ group. Notably, ZMW decreased liver weight but not adipose tissue weight. Furthermore, insulin resistance and hepatic mRNA expression of gluconeogenic genes, such as phosphoenolpyruvate carboxykinase and G6Pase, were improved in the HFD + ZMW $0.5 \%$ group. Furthermore, ZMW treatment decreased hepatic lipogenic gene expression; however, it did not alter adipogenesis in fat tissue, suggesting that ZMW inhibits hepatosteatosis through the suppression of lipogenesis. ZMW improved HFD-induced hepatic inflammation. Collectively, the present findings suggest that ZMW may serve as a new and promising strategy for the treatment of hepatosteatosis.
\end{abstract}

\section{Introduction}

Zingiber mioga (known as yangha in Korea, myoga in Japan and ranghe in China) is a perennial herb with short vegetative shoots that belongs to the ginger family (Zingiberaceae) (1). Z. mioga is widely cultivated in central and southeast China,

Correspondence to: Professor Chang Hwa Jung, Metabolic Mechanism Research Group, Korea Food Research Institute, 1-201 Anyangpangyo-ro, Bundang-ku, Seongnam, Gyeonggi 13539, Republic of Korea

E-mail: chjung@kfri.re.kr

Key words: Zingiber mioga, adipogenesis, insulin resistance, lipogenesis, hepatosteatosis
North Vietnam and South Korea (1). Z. mioga is used medicinally to treat coughing and rheumatism in China, and is widely consumed throughout Japan (2). Furthermore, Z. mioga is commercially cultivated on Jeju Island in South Korea. The leaves of $Z$. mioga are used to wrap and preserve manjyu, a popular traditional Japanese confection, due to their potent antimicrobial activity (3).

Numerous compounds have been extracted from Z. mioga. Mioganal, miogadial and miogatial are found at high levels in the flower buds. Additionally, high levels of galanal A and B are present in the leaves and rhizomes (3-6). These compounds have various biological activities, including anticancer, antimicrobial, anti-inflammatory and anti-platelet aggregation effects (3,6-8). Cho et al previously reported that Z. mioga can improve memory and neurocognitive performance (9). Although Z. mioga flower buds have various beneficial effects, including antimicrobial and anti-inflammatory properties, few studies have evaluated their anti-obesity effects $(10,11)$. A prior report suggested that $Z$. mioga inhibits fat accumulation in 3T3-L1 adipocytes and decreases body weight gain in mice (12); however, the molecular mechanism underlying this effect remains unclear.

In the current study, we investigated the effect of Z. mioga flower bud water extract (ZMW) on obesity and insulin resistance. To clarify the mechanisms underlying the regulation of obesity, the expression of lipid metabolism-associated genes in the liver and adipose tissue were analyzed. Furthermore, we examined the effect of ZMW on obesity-induced inflammation.

\section{Materials and methods}

Plant material and extract preparation. Z. mioga Roscoe flower buds were collected from a traditional market on Jeju Island (South Korea) in September 2013 and authenticated by Professor Seong-gyu Ko of the College of Oriental Medicine, Kyunghee University (Seoul, South Korea). A voucher specimen was deposited at the KFRI Herbarium (K00234) on September 23, 2012. Freshly picked plants were freeze-dried, ground using a mill and passed through a 50-mesh sieve. The ground powder was subjected to extraction with water or $70 \%$ ethanol twice using repeat sonication for $30 \mathrm{~min}$ at room temperature. The extract was filtered using a Whatman No. 2 paper filter (Advantec MFS, Inc., Dubulin, CA, USA) 
and concentrated using a vacuum evaporator (R-200; BÜCHI Labortechnik AG, Flawil, Switzerland). The extracts were freeze-dried and stored at $-80^{\circ} \mathrm{C}$.

Chemicals and reagents. Mouse anti- $\beta$-actin monoclonal antibody (sc-47778), rabbit anti-sterol regulatory element-binding protein (SREBP)-1c polyclonal antibody (sc-366), rabbit anti-CCAAT-enhancer-binding protein $\alpha(\mathrm{C} / \mathrm{EBP} \alpha)$ polyclonal antibody (sc-61), mouse anti-peroxisome proliferator-activated receptor (PPAR) $-\gamma$ monoclonal antibody (sc-7273), rabbit anti-phosphorylated (p)-nuclear factor (NF)- $\mathrm{KB}$ polyclonal antibody (sc-33039), rabbit anti-NF- $\mathrm{kB}$ polyclonal antibody (sc-109) and horseradish peroxidase (HRP)-conjugated anti-rabbit (sc-2004) and anti-mouse (sc-2005) secondary antibodies, were purchased from Santa Cruz Biotechnology, Inc. (Santa Cruz, CA, USA). Rabbit anti-p-AMP-activated kinase (AMPK; 2531), anti-AMPK (2532) and anti-FAS (318) polyclonal antibodies were purchased from Cell Signaling Technology, Inc. (Danvers, MA, USA). Oil Red O (O0625) and 3-(4,5-dime thylthiazol-2-yl)-2,5 diphenyltetrazolium bromide (MTT) were purchased from Sigma-Aldrich (St. Louis, MO, USA). Dulbecco's modified Eagle's medium (DMEM), fetal bovine serum (FBS), penicillin-streptomycin, bovine calf serum (CS) and phosphate-buffered saline (PBS) were obtained from Gibco (Thermo Fisher Scientific, Inc., Grand Island, NY, USA).

Cell culture and adipocyte differentiation. 3T3-L1 cells were purchased from the American Type Culture Collection (Manassas, VA, USA). Cells were cultured in DMEM containing $10 \% \mathrm{CS}, 100 \mathrm{U} / \mathrm{ml}$ penicillin and $100 \mu \mathrm{g} / \mathrm{ml}$ streptomycin at $37^{\circ} \mathrm{C}$ under $5 \% \mathrm{CO}_{2}$. The cells were seeded onto a 6-well plate $\left(4 \times 10^{5}\right.$ cells/well) and maintained for 2 days. To induce differentiation, 2-day post-confluent 3T3-L1 cells (day 0) were incubated in DMEM containing 0.5 mM 3-isobutyl-1-methylxanthine (IBMX; Sigma-Aldrich), $1 \mu \mathrm{M}$ dexamethasone (Sigma-Aldrich), $1 \mu \mathrm{g} / \mathrm{ml}$ insulin (Sigma-Aldrich) and 10\% FBS for 3 days. Following induction, the medium was replaced with DMEM containing 10\% FBS and $1 \mu \mathrm{g} / \mathrm{ml}$ insulin, and the cells were incubated for 2 days. Cells were then maintained in DMEM containing 10\% FBS until they reached maturity. Between days 0 and 3, the cells were exposed to Z. mioga extract.

Cytotoxicity assay. 3T3-L1 cells were seeded in a 96-well plate $\left(2 \times 10^{3}\right.$ cells/well). After $24 \mathrm{~h}$ of preconditioning, the cells were exposed to various concentrations of $Z$. mioga extracts for 24 or $48 \mathrm{~h}$. Subsequently, $50 \mu \mathrm{l}$ cell counting kit-8 solution (\#CK04; Dojindo Molecular Technologies, Inc., Kumamoto, Japan) was added to each well, and the plate was incubated for an additional $3 \mathrm{~h}$ at $37^{\circ} \mathrm{C}$, to detect cell survival. Cell viability was calculated by measuring the absorbance on a microplate reader (Infinite M200; Tecan US, Inc., Morrisville, NC, USA) at $450 \mathrm{~nm}$.

Oil Red $O$ staining. Cells were washed with PBS, fixed with $10 \%$ formalin for $1 \mathrm{~h}$ at room temperature, washed with PBS again and stained with filtered $0.5 \%$ Oil Red O solution in $60 \%$ isopropanol for $1 \mathrm{~h}$. After the stained lipid droplets were washed with distilled water, they were observed under a fluorescence microscope (IX71; Olympus Corporation, Tokyo, Japan). Oil Red O was extracted from the cells with $100 \%$ isopropanol, and the optical density was determined using a microplate reader (Infinite M200) at an excitation wavelength of $490 \mathrm{~nm}$.

Treatment of animals. Four-week-old male C57BL/6J mice were purchased from Orient Bio, Inc. (Seoul, South Korea) and acclimatized for 1 week prior to random assignment into experimental groups. The animals were housed in individual cages with free access to a regular diet and water in a room with a 12-h light cycle, a temperature of $24^{\circ} \mathrm{C}$ and a humidity of $55 \%$. The mice were divided into four groups: Normal group fed the American Institute of Nutrient-76 diet (AIN-76; $\mathrm{N}$ group); a group fed a high-fat diet (HFD; HFD group); and two groups fed a HFD with 0.25 or $0.5 \%$ ZMW (HFD + ZMW 0.25 or $0.5 \%$ groups). The experimental diets were based on the AIN-76 diet, which contained $20 \%$ fat and $0.5 \%$ cholesterol $(w / w)$. Animal studies were conducted in accordance with institutional and national guidelines, and all experimental procedures were approved by the Korea Food Research Institute Animal Care and Use Committee (\#2014-0120). After consuming the experimental diets for 8 weeks, the mice were subcutaneously anesthetized with Zoletil $50(30 \mathrm{mg} / \mathrm{kg}$; Virbac Philippines Inc., Taguig, Philippines) in PBS and then sacrificed by cervical dislocation. Blood samples were collected from the abdominal aorta. The liver and epididymal fat tissues were harvested in liquid nitrogen and stored at $-80^{\circ} \mathrm{C}$ for protein and RNA extraction.

Glucose tolerance test. The oral glucose tolerance test (OGTT) was performed after 8 weeks of ZMF administration. OGTT was determined in response to oral glucose administration $(1.2 \mathrm{~g} / \mathrm{kg}$ body weight) after fasting $12 \mathrm{~h}$. Blood glucose was collected from the tail vein $0,14,30,60$ and 120 min after oral glucose administration. Blood glucose concentrations were determined by the glucose oxidase method using a blood glucose monitoring meter (Accu-Chek ${ }^{\circledR}$ Performa Nano; Roche Diagnostics, Basel, Switzerland).

Total triglyceride (TG), total cholesterol (TC) and high-density lipoprotein (HDL) determination. TG, TC and HDL were measured enzymatically using commercial kits (cat. nos. 20267, 20186 and 20081, respectively; Shinyang Chemical Co., Ltd., Busan, South Korea).

Immunoblotting. Cells were harvested in lysis buffer (Sigma-Aldrich) containing $40 \mathrm{mM}$ HEPES (pH 7.4), $120 \mathrm{mM}$ $\mathrm{NaCl}, 1 \mathrm{mM}$ EDTA, $50 \mathrm{mM} \mathrm{NaF}, 1.5 \mathrm{mM} \mathrm{Na}_{3} \mathrm{VO}_{4}, 10 \mathrm{mM}$ $\beta$-glycerophosphate and $1 \%$ Triton X-100, supplemented with protease and phosphatase inhibitor cocktails (78440; Pierce; Thermo Fisher Scientific, Inc., Rockford, IL, USA). Protein concentration was determined using the Bradford protein assay. The proteins were separated by $7.5 \%$ sodium dodecyl sulfate-polyacrylamide gel electrophoresis (SDS-PAGE) and transferred to polyvinylidene fluoride (PVDF) membranes, followed by blocking with 5\% non-fat dry milk for $1 \mathrm{~h}$. Subsequently, the membranes were incubated overnight at $4^{\circ} \mathrm{C}$ with mouse anti- $\beta$-actin monoclonal antibody $(1: 2,000)$, rabbit anti-SREBP-1c polyclonal antibody $(1: 1,000)$, rabbit 

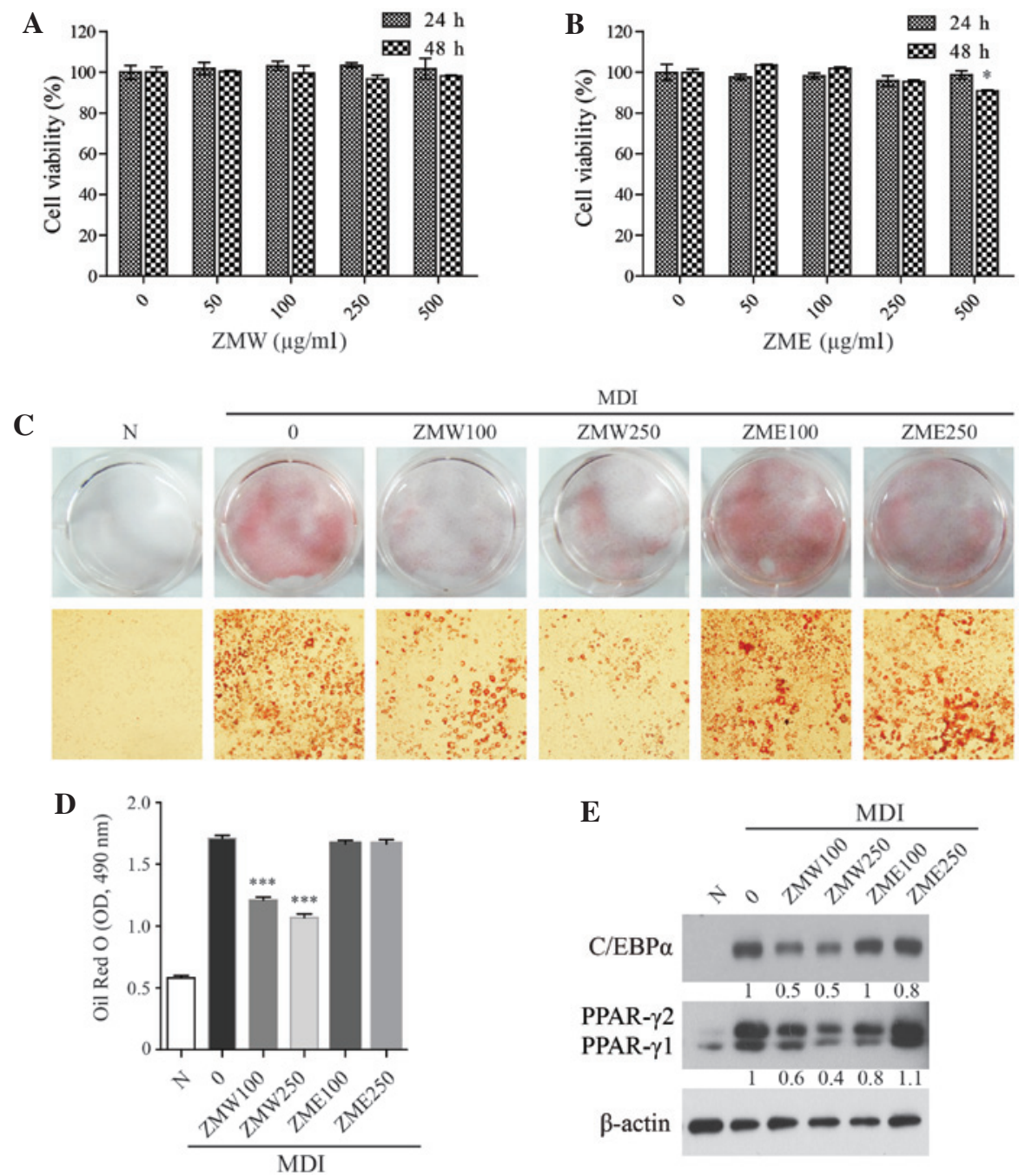

Figure 1. ZMW inhibits 3T3-L1 preadipocyte cell differentiation. Cell viabilities of (A) ZMW and (B) ZME was determined using the cell counting kit-8. (C) Oil Red O staining. (D) Quantitative analysis of the relative intensity of the Oil Red O stain. (E) Anti-adipogenic effects of ZMW; cell lysates were harvested into lysis buffer and analyzed by immunoblotting. ${ }^{*} \mathrm{P}<0.05 ;{ }^{* * *} \mathrm{P}<0.01$ vs. control group. ZMW, Zingiber mioga water extract; ZME, Z. mioga ethanol extract; MDI, OD, optical density; C/EBP $\alpha$, CCAAT-enhancer-binding protein alpha; PPAR, peroxisome proliferator-activated receptor; MDI, medium containing $0.5 \mathrm{mM}$ 3-IBMX, $1 \mu \mathrm{M}$ dexamethasone and $1 \mu \mathrm{g} / \mathrm{ml}$ insulin.

anti-C/EBP $\alpha$ polyclonal antibody $(1: 1,000)$, mouse anti-PPAR- $\gamma$ monoclonal antibody $(1: 1,000)$, rabbit anti-p-NF- $\mathrm{kB}$ polyclonal antibody $(1: 1,000)$, rabbit anti-NF- $\kappa \mathrm{B}$ polyclonal antibody $(1: 1,000)$, rabbit anti-p-AMPK polyclonal antibody $(1: 1,000)$, rabbit anti-AMPK polyclonal antibody $(1: 1,000)$ and rabbit anti-FAS polyclonal antibody $(1: 1,000)$, followed by washing with tris-buffered saline containing Tween-20 and incubation with HRP-conjugated anti-rabbit and anti-mouse $\operatorname{IgG}(1: 1,000$; Santa Cruz Biotechnology, Inc.) at room temperature for $1 \mathrm{~h}$. The bands were visualized using a chemiluminescence reagent (GE Healthcare, Little Chalfont, UK), and the relative intensities of the bands to $\beta$-actin signal was quantified by ImageJ software v1.45 (National Institutes of Health, Bethesda, MD, USA).

Reverse transcription-quantitative polymerase chain reaction $(R T-q P C R)$. Total RNA was extracted from $20-30 \mathrm{mg}$ liver tissue using a NucleoSpin RNA II kit (Macherey-Nagel GmbH \& Co. KG, Düren, Germany) according to the manufacturer's protocol. Following genomic DNA elimination with the gDNA elimination buffer in the RT ${ }^{2}$ First Strand kit (cat. no. 330401,
Qiagen, Inc. Valencia, CA, USA), cDNA was synthesized using $1 \mu \mathrm{g}$ RNA and the ReverTra Ace ${ }^{\circledR}$ qPCR RT kit (Toyobo, Co., Ltd., Osaka, Japan). qPCR was conducted on an StepOnePlus Real-time PCR system (Applied Biosystems; Thermo Fisher Scientific, Inc., Foster City, CA, USA) using SYBR Green real-time PCR Master Mix (Toyobo, Co., Ltd.) as follows: Pre-denaturation at $95^{\circ} \mathrm{C}$ for $5 \mathrm{~min}$, followed by 40 cycles of $95^{\circ} \mathrm{C}$ for $15 \mathrm{sec}, 60^{\circ} \mathrm{C}$ for $15 \mathrm{sec}$ and $75^{\circ} \mathrm{C}$ for $45 \mathrm{sec}$. The PCR reaction was performed in a volume of $20 \mu \mathrm{l}$, containing $2 \mu \mathrm{l}$ cDNA template and 10 pmol primers. The specific primer sequences were as follows: Phosphoenolpyruvate carboxykinase (PEPCK) forward, AAAAGCCTTTGGTCAACA AC and reverse, AAACTTCATCCAGGCAATGT; G6Pase forward, GAGTCTTGTCAGGCATTGCT and reverse, GGT ACATGCTGGAGTTGAGG; interleukin (IL)-6 forward, AGTTGCCTTCTTGGGACTGA and reverse, TCCACG ATTTCCCAGAGAAC; and tumor necrosis factor (TNF)- $\alpha$ forward, ACGGCATGGATCTCAAAGAC and reverse, AGA TAGCAAATCGGCTGACG. The experiment was conducted in duplicate with a negative control (no cDNA) and RT control (no reverse transcription). RNA levels were expressed as the 

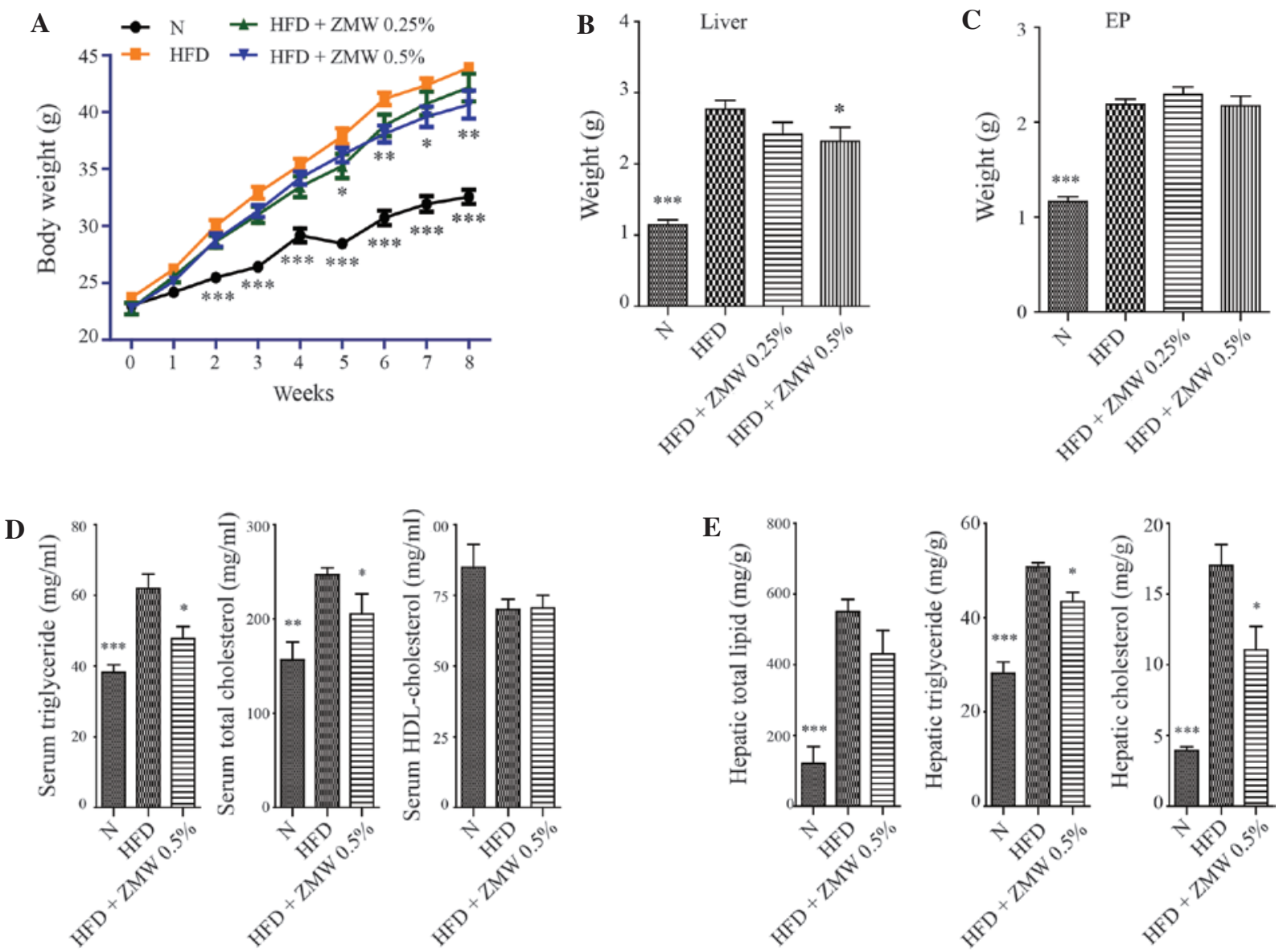

Figure 2. ZMW prevents HFD-induced obesity in C57BL/6 J mice. (A) Body weight of mice fed a HFD for 8 weeks. (B) Liver weight. (C) Epididymal fat tissue weight. Triglyceride and total cholesterol levels in the (D) serum and (E) hepatic tissue. Values presented as the mean \pm standard deviation ( $\mathrm{n}=8$ ). ${ }^{*} \mathrm{P}<0.05$; ${ }^{* *} \mathrm{P}<0.01 ;{ }^{* * *} \mathrm{P}<0.001$ vs. HFD group. N, normal control; HFD, high-fat diet; ZMW, Zingiber mioga water extract.

ratio of the signal intensity for each gene relative to $\beta$-actin and were calculated using the $2^{-\Delta \Delta C q}$ method (13).

Statistical analysis. Differences between groups were evaluated using a one-way analysis of variance (ANOVA) with Prism5 software (GraphPad Software, Inc., San Diego, CA, USA). The Bonferroni post-hoc correction for multiple comparisons was used when significant differences were identified using ANOVA $(\mathrm{P}<0.05)$. Data are expressed as the mean \pm standard deviation.

\section{Results}

ZMW inhibits 3T3-L1 preadipocyte cell differentiation. To establish the optimal extract concentration for use in vitro, the cells were treated with media containing $0-500 \mu \mathrm{g} / \mathrm{ml} \mathrm{ZMW}$ or Z. mioga ethanol extracts (ZME) for 24 or $48 \mathrm{~h}$. The viability of 3T3-L1 preadipocytes was not significantly affected by extract treatment up to $250 \mu \mathrm{g} / \mathrm{ml}$ (Fig. 1A and B). We next compared the inhibitory effects of the extract $(0-250 \mu \mathrm{g} / \mathrm{ml})$ on lipid accumulation during 3T3-L1 preadipocyte cell differentiation. Oil Red O staining was used to determine lipid droplet accumulation in 3T3-L1 adipocytes. ZMW significantly and dose-dependently inhibited lipid accumulation, whereas ZME had no effect (Fig. 1C and D). The expression of several proteins involved in adipogenesis, including C/EBP $\alpha$ and PPAR $\gamma$, were markedly suppressed by ZMW (Fig. 1E). These results suggest that ZMW, but not ZME, may have anti-obesity effects.

$Z M W$ reduces body and liver weight in HFD-fed mice. We next investigated whether ZMW was able to prevent HFD-induced obesity in mice. Total body and liver weight were significantly decreased in the HFD + ZMW $0.5 \%$ group, as compared to the HFD group (Fig. 2A and B). Unexpectedly, ZMW treatment did not affect adipose tissue weight (Fig. 2C), although ZMW inhibited adipogenesis in vitro.

$Z M W$ reduced serum and liver lipids. We next evaluated the effects of ZMW on the serum and liver lipid levels in mice fed HFD. ZMW significantly reduced the serum TG concentration (N, 37.5 \pm 2.3 ; HFD, $62.3 \pm 5.1$; HFD + ZMW 0.5\%, 48.3 \pm 4.2$)$ and TC $(\mathrm{N}, 162.0 \pm 14.2 ; \mathrm{HFD}, 243.2 \pm 14.3$; HFD + ZMW 0.5\%, 208.4 \pm 22.6 ) (Fig. 2D), although there was no significant difference in HDL cholesterol. Furthermore, hepatic TC and TG in the ZMW group were significantly reduced compared with the HFD group (Fig. 2E), although the total lipid levels in the ZMW group were not significantly different compared with the HFD group. These results indicate that ZMW effectively lowers serum and liver cholesterol.

$Z M W$ improves insulin resistance. Lipid accumulation in the liver can lead to insulin resistance by interfering with insulin 

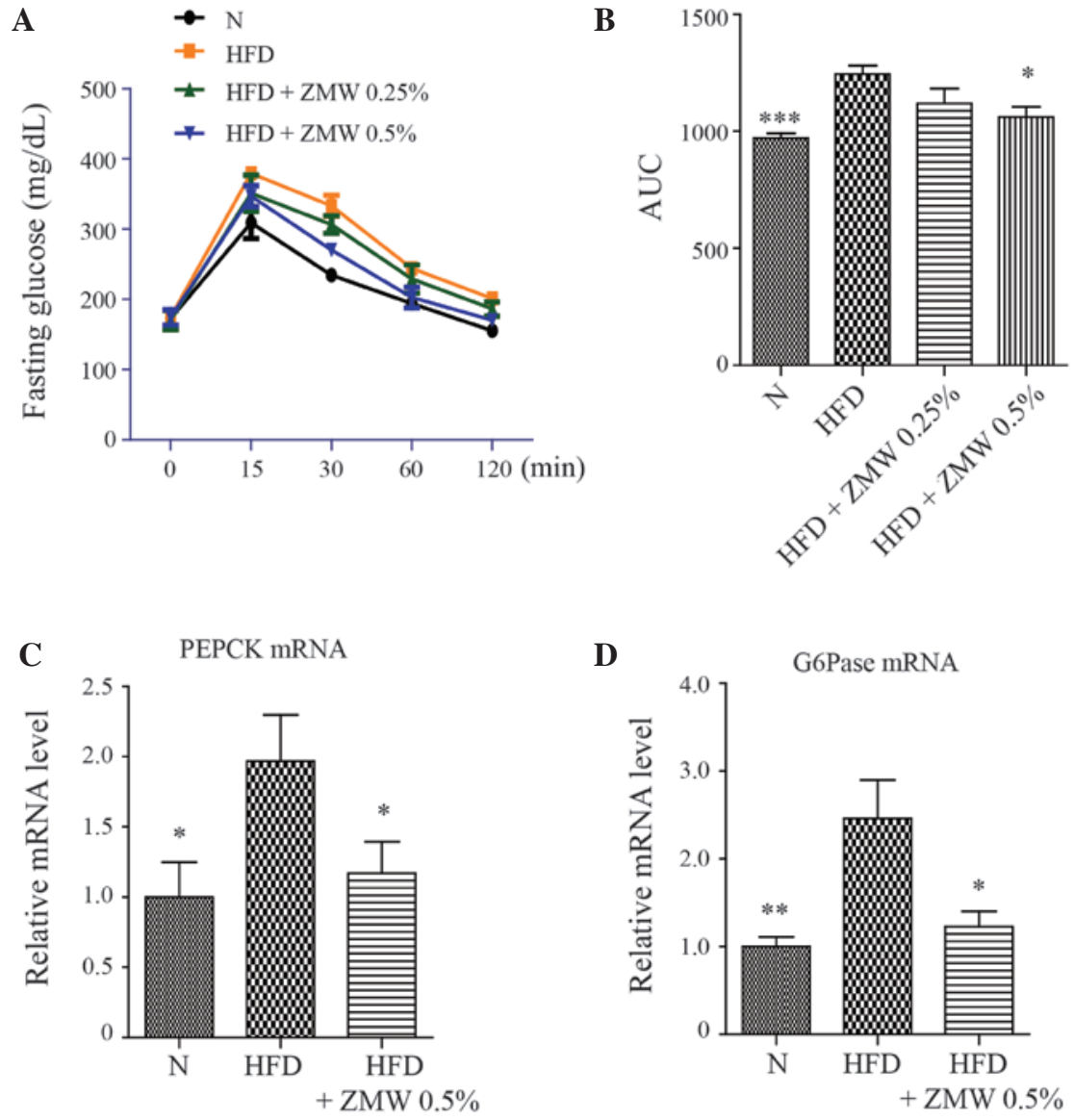

Figure 3. ZMW improves insulin resistance. (A) Time dependent blood glucose level followed by oral glucose administration. (B) AUC from oral glucose tolerance test. mRNA levels of (C) PEPCK and (D) G6Pase. Values presented as the mean \pm standard deviation $(\mathrm{n}=8){ }^{*} \mathrm{P}<0.05 ;{ }^{* *} \mathrm{P}<0.01 ;{ }^{* * * *} \mathrm{P}<0.001 \mathrm{vs}$. HFD group. N, normal control; HFD, high-fat diet; ZMW, Zingiber mioga water extract; AUC, area under the curve; PEPCK, phosphoenolpyruvate carboxykinase.

signal transduction (14). We next examined the effect of ZMW on insulin resistance in HFD-induced obese mice. The OGTT was used to evaluate insulin resistance. The ZMW group showed significantly lower blood glucose levels compared with the HFD group (Fig. 3A). Consequently, the area under the curve (AUC) in the ZMW group was significantly reduced $(\mathrm{P}<0.05)$ (Fig. 3B). To test the effect of ZMW on the expression of gluconeogenic genes, including PEPCK and G6Pase, the mRNA expression levels of PEPCK and G6Pase were determined using RT-qPCR. ZMW supplementation significantly reduced hepatic mRNA expression of PEPCK and G6Pase compared with the control group (Fig. 3C and D), indicating that HFD impairs hepatic insulin signaling, and ZMW supplementation effectively restores hepatic insulin sensitivity.

ZMW reduces the expression of lipid metabolism-associated genes in the liver, but not the epididymal fat. The AMPK signaling pathway serves a crucial function in liver lipid metabolism; when AMPK is activated, it inhibits the fatty acid and sterol synthesis pathway, and activates the fatty acid oxidation pathway (15). Furthermore, activated AMPK suppresses SREBP-1c, a lipogenesis-associated gene (16). Consistent with the reduced liver weight, western blot analysis indicated that ZMW treatment increased AMPK activation and decreased the SREBP-1c (Fig. 4A and B), although it did not suppress adipogenesis (Fig. 4C and D). These results suggest that ZMW may reduce body weight via the downregulation of hepatic lipogenesis.

ZMW ameliorates hepatic inflammation. Diet-induced obesity triggers inflammatory responses (17). When hepatic proinflammatory cytokine mRNA levels were examined, HFD-fed mice displayed a significant increase in IL-6, although TNF- $\alpha$ levels were slightly decreased, as compared with normal mice (Fig. 5A and B). The increased IL-6 levels were significantly decreased by ZMW supplementation (Fig. 5A). However, ZMW had no effect on TNF- $\alpha$ levels (Fig. 5B). We also examined whether $\mathrm{ZMW}$ inhibits $\mathrm{NF}-\kappa \mathrm{B}$ activation (Fig. $5 \mathrm{C}$ and $\mathrm{D}$ ). ZMW reduced NF- $\kappa \mathrm{B}$ phosphorylation, indicating that ZMW ameliorates HFD-induced inflammatory enzymes, such as $\mathrm{NF}-\kappa \mathrm{B}$. Collectively, the present results suggest that ZMF improves hepatic steatosis while decreasing liver inflammation.

\section{Discussion}

Z. mioga is also a traditional medicine that is used to relieve insect bites, eye inflammation, cough and rheumatism $(2,18)$. $Z$. mioga is a member of the ginger family and its biological function is unclear. It was previously reported that Z. mioga exerts an anti-obesity effect (12); however, the mechanism underlying obesity inhibition remains unclear. In the present study, ZMW inhibited adipogenesis in vitro, whereas ZME 

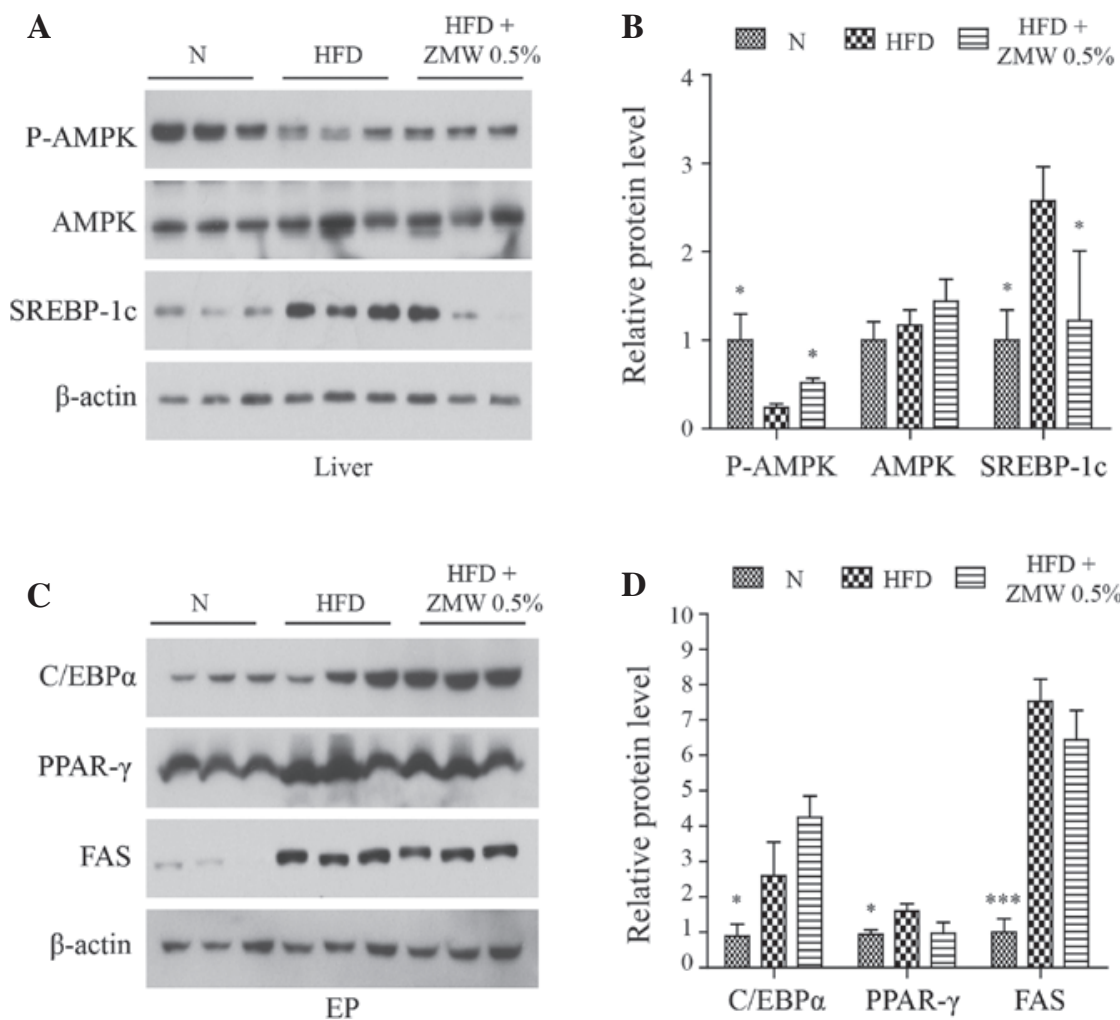

Figure 4. ZMW reduces the expression of liver lipid metabolism-related. (A) AMPK and SREBP-1c levels in the liver were detected by immunoblotting. (B) Densitometric levels were obtained using Image J software and relative protein levels were normalized against $\beta$-actin. (C) Adipogenesis-associated genes in epididymal fat tissue. (D) Relative protein levels calculated using ImageJ. Values are presented as the mean \pm standard deviation $(\mathrm{n}=3)$. ${ }^{*} \mathrm{P}<0.05 ;{ }^{* * * *} \mathrm{P}<0.001$ vs. HFD group. N, normal control; HFD, high-fat diet; ZMW, Zingiber mioga water extract; AMPK, AMP-activated protein kinase; SREBP-1c, sterol regulatory element-binding protein 1; C/EBP $\alpha$, CCAAT-enhancer-binding protein alpha; PPAR, peroxisome proliferator-activated receptor.
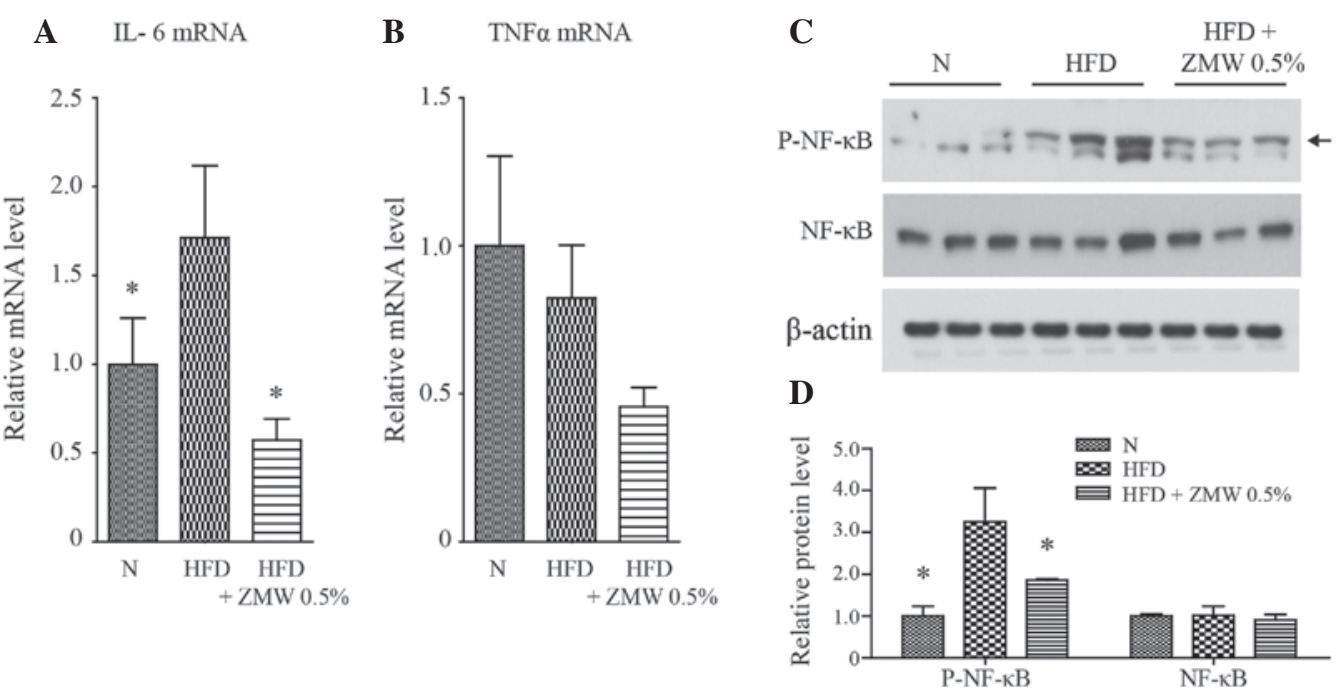

Figure 5. ZMW ameliorates hepatic inflammation in HFD-fed mice. mRNA levels of (A) IL-6 and (B) TNF $\alpha$ in the liver. (C) Expression of NF- $\mathrm{kB}$ in the liver. (D) Relative levels of NF- $\mathrm{KB}$ protein expression normalized against $\beta$-actin. Values are presented as the mean \pm standard deviation $(\mathrm{n}=3)$. "P<0.05 vs. HFD group. IL-6, interleukin-6; TNF $\alpha$, tumor necrosis factor alpha; N, normal control; HFD, high-fat diet; ZMW, Zingiber mioga water extract; NF-кB, nuclear factor kappa B.

had no effect. Several studies have characterized the chemical composition and biological activity of Z. mioga $(5-7,19)$. Phenolic compounds are more abundant in ZMW compared with ZME (9), indicating that the phenolic compounds are water soluble, which is unique as the majority of phenolic compounds are hydrophobic. Miogadial, galanal A and galanal B have been identified in Z. mioga, and display potent anticancer activity in vitro, as compared with other ginger-specific constituents (7). However, these compounds were isolated from the ethyl acetate fraction and are water insoluble (5). Thus, these compounds are likely to not be involved in the anti-obesity effects. Rather, water-soluble 
compounds are responsible for the inhibiting adipogenesis. Flavor components were also identified, with numerous terpenes, including $\beta$-pinene, $\beta$-terpinene, $\beta$-phellandrene, $\alpha$-pinene and 1,4-terpineol (20).

In animal models, the present results showed that $\mathrm{ZMW}$ lowers body weight and serum and hepatic lipid levels in HFD-fed mice. ZMW also attenuates the increase in liver weight observed in mice fed with a HFD. Western blot data indicated that ZMW effectively suppresses SREBP-1c protein expression, a lipogenic gene, and restores AMPK activation. These results are consistent with previous work that showed AMPK activation suppresses SREBP-1c cleavage and nuclear translocation (16). Unlike the in vitro studies, ZMW administration did not decrease adipose tissue weight, although ZMW markedly inhibited adipogenesis during 3T3-L1 cell differentiation. Furthermore, the HFD + ZMW 0.5\% group did not alter $\mathrm{C} / \mathrm{EBP} \alpha$ and PPAR $\gamma$ expression in epididymal white adipose tissue, as compared with the mice that received a HFD. It is possible that ZMW does not penetrate the fat tissue, or that levels were too low for an effect. These results also suggest that $\mathrm{ZMW}$ is able to reduce body weight without decreasing adipose tissue fat accumulation.

A HFD has been shown to affect lipid and glucose metabolism, impair insulin sensitivity and induce inflammation $(15,21,22)$. In the present study, ZMW reversed the HFD-induced insulin resistance. Furthermore, decreased PEPCK and G6Pase gene expression was observed in the liver tissue of the HFD + ZMW group, suggesting that reduced gluconeogenesis may contribute to improved insulin sensitivity. Inflammation has an important role in the pathogenesis of obesity-related insulin resistance $(15,23)$. The proinflammatory cytokines IL- 6 and TNF $\alpha$ mediate insulin action and glucose transport through multiple targets $(22,24)$. Therefore, we evaluated the effects of ZMW treatment on the expression of cytokines in the liver. The data presented herein showed that ZMW reduced the expression of IL- 6 in the liver, as compared with the HFD group. However, hepatic TNF- $\alpha$ expression was not significantly different between the normal and HFD groups, which differs from previous studies $(25,26)$. It is possible that HFD administration for 4 weeks may not markedly increase inflammation. Additionally, it was found that the HFD upregulated the phosphorylation of $N F-\kappa B$ genes, which were significantly reduced following $\mathrm{ZMF}$ supplementation.

Collectively, the results of in vivo experiments support the anti-obesity effect of Z. mioga. ZMW may function by inhibiting hepatic gluconeogenesis, resulting in increased insulin sensitivity and reduced inflammation. The present study supports the further investigation of $\mathrm{ZMW}$ as a potential anti-hepatic steatosis agent.

\section{Acknowledgements}

The present study was supported by the Korea Food Research Institute (grant no. E0080201-08).

\section{References}

1. Cole TCH and Nürnberger S: Zingiber mioga and its cultivars. Plantsman: New Series 14: 226, 2014.
2. Mihashi $\mathrm{H}$ and Okada M: Illustrated medicinal plants of the world in colour. Hokuryūkan Co., Ltd., Tokyo, pp666, 1988 (In Japanese).

3. Abe M, Ozawa Y, Uda Y, Yamada F, Morimitsu Y, Nakamura Y and Osawa T: Antimicrobial activities of diterpene dialdehydes, constituents from myoga (Zingiber mioga Roscoe), and their quantitative analysis. Biosci Biotechnol Biochem 68: 1601-1604, 2004.

4. Abe M, Ozawa Y, Morimitsu Y and Kubota K: Mioganal, a novel pungent principle in myoga (Zingiber mioga Roscoe) and a quantitative evaluation of its pungency. Biosci Biotechnol Biochem 72: 2681-2686, 2008.

5. Abe M, Ozawa Y, Uda Y, Yamada F, Morimitsu Y, Nakamura Y and Osawa T: Labdane-type diterpene dialdehyde, pungent principle of myoga, Zingiber mioga roscoe. Biosci Biotechnol Biochem 66: 2698-2700, 2002.

6. Abe M, Ozawa Y, Uda Y, Morimitsu Y, Nakamura Y and Osawa T: A novel labdane-type trialdehyde from myoga (Zingiber mioga Roscoe) that potently inhibits human platelet aggregation and human 5-lipoxygenase. Biosci Biotechnol Biochem 70: 2494-2500, 2006.

7. Miyoshi N, Nakamura Y, Ueda Y, Abe M, Ozawa Y, Uchida K and Osawa T: Dietary ginger constituents, galanals $\mathrm{A}$ and $\mathrm{B}$, are potent apoptosis inducers in Human T lymphoma Jurkat cells. Cancer Lett 199: 113-119, 2003.

8. Kim HW, Murakami A, Abe M, Ozawa Y, Morimitsu Y, Williams MV and Ohigashi H: Suppressive effects of mioga ginger and ginger constituents on reactive oxygen and nitrogen species generation, and the expression of inducible pro-inflammatory genes in macrophages. Antioxid Redox Signal 7: 1621-1629, 2005.

9. Cho KH, Oh MS, Kim GH, Lee SH, Chung KS and Kim AJ: Effects of Korean Zingiber mioga R. (Flower Buds and Rhizome) extract on memory. J Korean Soc Food Sci Nutr 43: 1519-1526, 2014.

10. Shin JH, Lee SJ and Sung NJ: Effects of Zingiber mioga, Zingiber mioga root and Zingiber officinale on the lipid concentration in hyperlipidemic rats. J Korean Soc Food Sci Nutr 31: 679-684, 2002

11. Iwashita K, Kohji Y and Tsushida T: Mioga (Zingiber mioga Rosc.) extract prevents 3T3-L1 differentiation into adipocytes and obesity in mice. Food Sci Technol Res 7: 164-170, 2001.

12. Iwashita K, Wamaki K and Tsushida T: Mioga (Zingiber mioga Rosc.) extract prevents 3T3-L1 differentiation into adipocytes and obesity in mice. Food Sci Tech Int 7: 164-170, 2001.

13. Livak KJ and Schmittgen TD: Analysis of relative gene expression data using real-time quantitative PCR and the 2(-Delta Delta C(T)) Method. Methods 25: 402-408, 2001.

14. Chan SM, Sun RQ, Zeng XY, Choong ZH, Wang H, Watt MJ and Ye JM: Activation of PPAR $\alpha$ ameliorates hepatic insulin resistance and steatosis in high fructose-fed mice despite increased endoplasmic reticulum stress. Diabetes 62: 2095-2105, 2013.

15. Qatanani M and Lazar MA: Mechanisms of obesity-associated insulin resistance: Many choices on the menu. Genes Dev 21: 1443-1455, 2007.

16. Li Y, Xu S, Mihaylova MM, Zheng B, Hou X, Jiang B, Park O, Luo Z, Lefai E, Shyy JY, et al: AMPK phosphorylates and inhibits SREBP activity to attenuate hepatic steatosis and atherosclerosis in diet-induced insulin-resistant mice. Cell Metab 13: 376-388, 2011.

17. Woo SL, Xu H, Li H, Zhao Y, Hu X, Zhao J, Guo X, Guo T, Botchlett R, Qi T, et al: Metformin ameliorates hepatic steatosis and inflammation without altering adipose phenotype in diet-induced obesity. PloS One 9: e91111, 2014.

18. Wiart C: Medicinal Plants of China, Korea, and Japan: Bioresources for Tomorrow's Drugs and Cosmetics. 1st edition. CRC Press, Boca Raton, FL pp67, 2012

19. Kurobayashia Y, Sakakibara H, Yanai T, Yajima I and Hayashi K: Volatile Flavor Compounds of Myoga (Zingiber mioga). Agric Biol Chem 55: 1655-1657, 1991.

20. Lee JW, Chon SU, Han SK, Choi DG and Ryu J: Effects of antioxidant and flavor components of Zingiber mioga Rosc. Han'guk Yakyong Changmul Hakhoe Chi 15: 203-209, 2007 (In Korean).

21. Jung S, Lee MS, Shin Y, Kim CT, Kim IH, Kim YS and Kim Y: Anti-obesity and anti-inflammatory effects of high hydrostatic pressure extracts of ginseng in high-fat diet induced obese rats. J Funct Foods 10: 169-177, 2014.

22. de Luca $\mathrm{C}$ and Olefsky JM: Inflammation and insulin resistance. FEBS Lett 582: 97-105, 2008. 
23. Xu H, Barnes GT, Yang Q, Tan G, Yang D, Chou CJ, Sole J, Nichols A, Ross JS, Tartaglia LA and Chen H: Chronic inflammation in fat plays a crucial role in the development of obesity-related insulin resistance. J Clin Invest 112: 1821-1830, 2003.

24. Roytblat L, Rachinsky M, Fisher A, Greemberg L, Shapira Y, Douvdevani A and Gelman S: Raised interleukin-6 levels in obese patients. Obes Res 8: 673-675, 2000
25. van der Heijden RA, Sheedfar F, Morrison MC, Hommelberg PP, Kor D, Kloosterhuis NJ, Gruben N, Youssef SA, de Bruin A, Hofker MH, et al: High-fat diet induced obesity primes inflammation in adipose tissue prior to liver in C57BL/6j mice. Aging (Albany NY) 7: 256-268, 2015.

26. Borst SE and Conover CF: High-fat diet induces increased tissue expression of TNF-alpha. Life Sci 77: 2156-2165, 2005. 